\title{
RELIGIÃO E MORTE: QUAL A RELAÇÃO EXISTENTE? ${ }^{1}$
}

\author{
Carine dos Reis Silva Enfermeira. Pós-graduanda em Enfermagem \\ Oncológica
}

\author{
Sandra Dutra Cabral Portella Enfermeira. Mestre pela Universidade Federal \\ do Estado da Bahia. Professora Assistente da \\ Universidade do Estado da Bahia
}

\author{
Luciano Rodriguez Reis
}

Enfermeiro. Mestre em Saúde Pública pela Universidade Federal da Bahia. Professor Assistente da Universidade do Estado da Bahia

\section{Tânia Christiane Ferreira Bispo}

\author{
Enfermeira. Doutora em Saúde e mestre em \\ Enfermagem pela Pública pela Universidade \\ Federal da Bahia. Professora Adjunta da \\ Universidade do Estado da Bahia
}

\begin{abstract}
Resumo
A morte sempre foi um grande mistério para a humanidade. Na tentativa de entendê-la e achar respostas sobre o fenômeno, o homem desde os tempos remotos busca na religião apoio e explicações sobre a sua finitude e principalmente sobre a possibilidade de continuação após sua morte. Analisar a relação existente entre religiosidade e aceitação da morte é de extrema importância para a prestação de uma melhor assistência de enfermagem para o paciente considerado terminal. Realizamos entrevistas semiestruturadas com enfermeiros, individualmente, de forma que pudessem expressar suas percepções a cerca da aceitação da morte e religiosidade. Para a análise de conteúdo nos baseamos em Minayo, evidenciado que há uma melhor aceitação da eminência da morte e do sofrimento nos pacientes considerados religiosos e que diante da possibilidade da finitude os pacientes se apegam mais a religião.
\end{abstract}

Palavras-chave: Morte; Religião; Enfermagem.

\section{RELIGION AND DEATH: WHAT IS THE RELATION SHIP?}

\begin{abstract}
Death has always been a mystery to mankind. In an attempt to understand it and find answers about the phenomenon, the man since ancient times seeking support in religion and explanations about their finitude and especially about the possibility of continuing after his death. Analyze the relationship between religiosity and acceptance of death is extremely important to provide better nursing care for the terminal patient. We conducted semistructured interviews with nurses, individually, so they could express their perceptions about the acceptance of death and religiosity. For the content analysis we rely on Minayo, demonstratedthat there is greater acceptance of the imminence of death and suffering in patients considered religious and facing the possibility of finitude patients cling more to religion.
\end{abstract}

Keywords: Death; Religion; Nursing.

\footnotetext{
${ }^{1}$ Parte da monografia Percepção dos enfermeiros quanto à reação dos pacientes frente à eminência da morte, apresentada em 2012 à disciplina Seminário Integrado do Curso de Graduação em Enfermagem na Universidade do Estado da Bahia (UNEB), Salvador, Bahia, Brasil.
} 


\title{
RELIGIÓN Y MUERTE: CUAL ES LA RELACIÓN EXISTENTE?
}

\begin{abstract}
Resumen
La muerte siempre fue un gran misterio para la humanidad. En el intento de entender y encontrar respuestas sobre el fenómeno, el hombre desde los tiempos remotos busca en la religión apoyo y explicaciones sobre su finitud y principalmente sobre la posibilidad de existir vida después de la muerte. Analizar la relación que existe entre religiosidad y aceptación de la muerte es de suma importancia para mejorar el auxilio o ayuda que la enfermería ofrece al paciente considerado en fase terminal. Realizamos entrevistas semi-estructuradas con enfermeros, individualmente, de forma que pudiesen expresar sus percepciones referentes a la aceptación de la muerte y de la religiosidad. Para el análisis de contenido nos basamos en Minayo, que evidencia que existe una mejor aceptación de la eminencia de la muerte y del sufrimiento en los pacientes considerados religiosos y que delante de la posibilidad de la finitud los pacientes se apegan mas a religión.
\end{abstract}

Palabras clave: Muerte; Religión; Enfermería.

\section{INTRODUÇÃO}

Tentar explicar como se dá a finitude da vida e o futuro após a morte é uma tarefa muito subjetiva e ao mesmo tempo intrigante para os homens. A partir de tamanha procura e desafio, o homem busca através da religião encontrar explicações que lhe confortem ou que pelo menos lhe tragam respostas para suas angústias e medo.

São grandes os mistérios que cercam o homem: sua origem, seu papel no mundo e a sua finitude. Na tentativa de entender e explicar tais mistérios, o homem se aproxima dos conhecimentos filosóficos, científicos e religiosos, a fim de encontrar suas respostas. Sendo a morte o mistério mais aterrorizante que cerca o homem, é o terror de deixar de existir. ${ }^{(1)}$

Assim, entende-se que como forma de desvendar o mistério que cerca a morte, o homem se aproxima, desde os tempos antigos aos atuais, da religião.

Estudos antropológicos afirmam que a ignorância do homem a respeito de suas enfermidades, proporcionou que em determinado momento da história da humanidade houvesse o processo de divinização do desconhecido, acreditando assim que deuses tinham poder de causar e curar doenças e que apenas seus representantes na terra podiam interferir no processo saúde-doença e nos fenômenos vida-morte. ${ }^{(2)}$ Dessa forma, ao longo dos anos a religião veio acompanhando o homem durante toda sua história, enraizando-se em seus costumes, cultura e influenciando na formação do conceito de moral e ética, e servindo assim, como base para os relacionamentos interpessoais. Por tanto, o ser humano absorveu normas e pensamentos religiosos a cerca de diversos temas como vida e morte.

Para o paciente, uma das formas de enfrentar o medo da morte, da doença, da invalidez e da solidão é buscando ideias, pensamentos que tragam amparo, conforto e até mesmo solução para seus problemas. Entender o porquê do sofrimento e da morte pode ser 
um alívio em meios a tantas dúvidas e desconhecimento em relação ao seu próprio futuro. Logo, através de conceitos religiosos os pacientes encontram muitas "respostas" mesmo subjetivas que respondem as suas indagações.

Assim, os profissionais de saúde, especialmente os enfermeiros, precisam entender a relação existente entre o paciente e a religiosidade, respeitando e acolhendo as ideias e experiências vivenciadas por estes. É preciso valorizar a cultura e crença do outro, para assim melhor cuidar e entender de todos os seus aspectos humanos, físicos, mentais, sociais e espirituais.

O profissional de saúde, ao identificar as necessidades espirituais - religiosas do paciente, pode ajudar o mesmo a melhor lidar com sua doença. Pode ainda propiciar uma melhor relação paciente-profissional, fortalecer a adesão e a crença no tratamento. Assim há um cuidar mais satisfatório. ${ }^{(1)}$

Utilizando-se da pesquisa de campo, através de entrevistas semiestruturadas esta pesquisa teve como proposta discutir como os enfermeiros percebem a relação existente entre religião e morte na vivência do paciente terminal.

\section{METODOLOGIA}

Trata-se de uma pesquisa de abordagem qualitativa, e de caráter descritivo. A opção pela pesquisa qualitativa deve-se ao fato de ser um método de investigação que enfatiza a compreensão da experiência humana como é vivida, através da coleta e analise dos materiais narrativos, subjetivos, onde se permite a compreensão dos comportamentos das pessoas em determinadas situações. ${ }^{(3)}$

O delineamento adotado na pesquisa foi o estudo de campo. Pois, possibilita o pesquisador realizar o trabalho pessoalmente, devido à importância de se ter uma experiência direta com a situação investigada, tendo-se, dessa forma, maior probabilidade de os sujeitos oferecerem respostas mais confiáveis. ${ }^{(4)}$

A pesquisa foi realizada em um Hospital Filantrópico de Alta Complexidade localizado no município de Salvador-BA. A referida instituição presta atendimento a pacientes possuidores de convênios e usuários do Sistema Único de Saúde (SUS).

Foram realizadas entrevistas semiestruturadas e individuais com dez enfermeiros, com idade entre 25 e 39 anos, com um ano a treze anos de serviço na Instituição e que atuavam na unidade de oncologia. O critério adotado para seleção dos sujeitos da pesquisa era o 
profissional enfermeiro que possuía mais de um ano de serviço na Instituição, independente de idade ou gênero. Na intenção que os enfermeiros revelassem seus pensamentos em relação à religiosidade e aceitação da morte, elaboramos questões norteadoras: Você nota alguma diferença em relação à aceitação da morte entre o paciente religioso e/ou não religioso? Você acha que a religião influencia na aceitação ou entendimento a respeito da morte?

Após transcrevermos, integralmente, os discursos dos sujeitos da pesquisa, analisamos os discursos utilizando o método operacionalizado por Minayo, proposto em quatro fases: pré-análise, exploração do material, tratamento dos resultados obtidos e interpretação. ${ }^{(5)}$ Procedeu-se a leitura integral das entrevistas e o conteúdo dos dados foram divididos em duas categorias: Influencia da religião na aceitação da morte e Apego a religião diante da possibilidade da morte.

Os aspectos éticos observados para o desenvolvimento desse estudo foram com base na Resolução 196/96 do Conselho Nacional de Saúde. ${ }^{(6)}$ O projeto foi apreciado e aprovado pelo Comitê de Ética em Pesquisa - Monte Tabor/ Hospital São Rafael (protocolo CEPHSR no22 /11). Para preservar o anonimato dos enfermeiros, todos receberam nomes de flores. Os enfermeiros que se dispuseram a participar deste estudo, após os esclarecimentos, assinaram o Termo de Consentimento Livre e Esclarecido.

\section{RESULTADOS E DISCUSSÃO}

Para muitos pacientes a religião surge como um apoio nos momentos de sofrimento e medo, até mesmo como esperança na cura ou num destino melhor no caso da sua morte. Porém, alguns pacientes entendem e utilizam de suas interpretações religiosas e procura ligalas a fatos relacionados à sua doença, ou seja, alguns podem interpretar como castigo, como provação ou até mesmo como uma proposta de melhora ou "purificação" da vida.

É muito difundida a ideia de que a religião tem como objetivo aplacar os temores diante do ininteligível. Assim, a religião teria finalidades utilitárias, tendo a função de organizar defesas contra os medos do aniquilamento. ${ }^{(7)}$

No final de 1980, epidemiologistas americanos iniciaram um cruzamento de dados que relacionavam práticas da espiritualidade/religiosidade, tais como frequência religiosa e de orações com indicadores de saúde, doença e longevidade.$^{(1)} \mathrm{E}$ a partir desses dados, contatouse que a espiritualidade e a religiosidade estavam associadas com a melhor qualidade de vida, mais longevidade e menos doença física e mental. Milhares de artigos vêm sendo publicados 
em revistas médicas mostrando, na sua maioria, há associação positiva existente entre práticas espirituais e saúde. ${ }^{(1)}$

\section{INFLUENCIA DA RELIGIÃO NA ACEITAÇÃO DA MORTE}

O paciente vivencia a proximidade da morte de acordo com a interação entre as crenças religiosas introjetadas durante toda a sua vida e segundo a intensidade e qualidade dos mecanismos projetivos utilizados. ${ }^{(1)}$

Assim, quando questionados sobre a influência que a religião exerce na aceitação da morte pelo paciente, alguns enfermeiros entenderam que a religião exerce essa influencia, pois eles percebem que um paciente religioso possui atitudes que mostram maior conformismo e entendimento sobre a proximidade de sua morte. Os discursos abaixo relatam este fato:

[...] O paciente que tem uma religião ele é mais flexível para você conseguir estar fazendo com que ele aceite né, porque tem que se apegar a alguma coisa né, há alguma necessidade, por que se não! [...] Ele aceita de uma forma mais visível. Ele fica mais tranquilo, mais calmo, não é nem relaxado à palavra assim, mas ele tem onde se apegar [...] (Rosa).

[...] pessoas que tinham uma formação religiosa, acreditavam no algo mais, ela aceita com mais facilidade, pessoas que não tinham uma formação religiosa, pessoa mais materialista tem dificuldade [...] (Cravo).

[...] os pacientes que são voltados a qualquer tipo de religiosidade, que aceita, que compreende, e chegando esse momento eles têm uma boa aceitação (Flor de Lis).

Há uma diminuição do medo entre as pessoas que possuem alguma crença religiosa, sendo que os religiosos e os ateus convictos têm menos medo da morte que os medianamente envolvidos. ${ }^{(8)}$

Percebemos que há um melhor enfrentamento da morte pelos pacientes que possuem uma crença religiosa ou buscam sua espiritualidade. Segundo alguns enfermeiros entrevistados, a religião ajuda o paciente a melhor aceitar a morte e agirem com maior tranquilidade e clareza diante da sua terminalidade, além de estarem mais desvinculados dos processos e laços materiais e terrenos.

Revista Enfermagem Contemporânea, Salvador, dez. 2012; 1(1): 130-141. 
Continuamos com o relato abaixo, segundo um enfermeiro, de uma paciente que após diversos internamentos e anos de luta contra a doença, refere aceitar bem sua partida para o "lado de Deus", mesmo intimamente desejando continuar a viver se fosse possível.

[...] e aí ela contando a história: volto agora já velhinha, já com metástase pra tudo quanto é lugar, parei de fumar porque eu sei que eu fumei, fumei e agora estou com metástase pra tudo quanto é lugar e sei que agora eu vim, e eu indo pro lado de lá, que vou estar muito melhor do que estando aqui e aceito como assim uma forma, não que aqui eu não tenha uma vida boa, posso ficar aqui até viver mais, continuar, mas eu tenho com certeza que no lado de Deus eu vou estar muito melhor [...] (Girassol).

Outros enfermeiros referiram não perceber nenhum tipo de relação, por nunca terem feito esse tipo de análise ou preferirem se afastar de qualquer julgamento religioso. Pode-se verificar esta situação nos depoimentos abaixo:

\section{[...] Não consigo perceber essa diferença (Violeta).}

Olha, eu nunca fiz essa análise, nunca pensei por esse lado não. Mas eu não percebo diferença assim. [...] Eu acredito assim, pelo menos ao ver a religião não influencia [...] (Orquídea).

Olhe, nunca percebi essa diferença, até porque eu prefiro não entrar nesse contexto de religião com o paciente [...] (Margarida).

Muitos autores demonstram a importância que a religiosidade e espiritualidade possuem na melhora do enfrentamento da doença e da morte em alguns pacientes. Porém, não anulamos a ideia que mesmo o paciente que não possui nenhum tipo de crença religiosa tenha forças para enfrentar e melhor aceitar seu adoecimento e futura morte.

Mesmo as pessoas que não possuem religião ou tradição, possuem qualidades humanas tão validas quanto as que possuem uma crença religiosa, pois a abordagem da morte é uma abordagem humana. Logo, entende-se que a função da religião está em despertar e revelar essas qualidades humanas profundas. ${ }^{(9)}$

Muitos profissionais de saúde buscam separar a questão religiosa do seu processo de cuidar, talvez por reflexo de sua realidade de vida e crença, por não encontrarem importância nesse tipo de diálogo com o paciente ou até mesmo por não se sentirem capacitados nesse tipo de abordagem.

Os profissionais podem encontrar como barreira para relacionar as práticas religiosas com o cuidar: a falta de conhecimento sobre o assunto, pouco treinamento e tempo para 
trabalhar o tema, desconforto com o assunto, medo de impor visões religiosas ou ofender o paciente, acreditar que o conhecimento sobre religião não seja importante para os cuidados e achar que não é de sua competência abordar tais assuntos. ${ }^{(1)}$

Dessa forma, entendemos que seria importante para o enfermeiro buscar conhecer os principais aspectos religiosos que interferem na vida do paciente, pois é necessário lembrarmos que com a proximidade da morte muitos pacientes sentem-se acolhidos e apoiados em sua religião. Assim, devemos buscar compreender que a dimensão espiritual faz parte da holística humana, e porque não entendê-la?

A partir de uma avalição sobre a história espiritual do paciente deve-se entender a importância disso na vida do paciente e de sua família, para assim incluir tais abordagens nos cuidados ao paciente. Sendo que os profissionais devem trabalhar as crenças e a fé do paciente sem pregar a sua verdade. ${ }^{(1)}$

\section{APEGO À RELIGIÃO DIANTE DA POSSIBILIDADE DA MORTE}

Nesta categoria os enfermeiros relatam que diante de uma situação de sofrimento, doença e morte os pacientes muitas vezes se apegam em suas crenças religiosas ou espirituais para assim conseguirem superar ou mesmo encontrar equilíbrio em meio ao turbilhão de sentimentos, pensamentos e situações que vivem. Foi possível observar tais afirmações nos depoimentos a seguir:

[...] Então quando ela aceita a eminência da morte, ela acaba se apegando a alguma coisa, às vezes se apegada demais à família, às vezes se apega demais a uma religião, alguma..., tipo assim, o espiritismo mesmo, às vezes têm muitas pessoas que se apega ao espiritismo, porque o espiritismo prega que há um algo além, né? [...] (Cravo).

Como se pode perceber nas falas abaixo, o enfermeiro aponta como é importante para o paciente receber o auxílio através do seu representante religioso ou do grupo religioso a qual pertence:

[...] Geralmente eles solicitam auxílio religioso, é eles preferem realmente, estou puxando aqui pela memória, pede, por exemplo, um pastor, conversar com os familiares, mas um padre [...] (Jasmim).

Então ela toda à tarde, ela fazia quimioterapia de manhã, toda tarde vinha aquele grupo, e botavam a mão, aí ela ficava toda tarde, toda tarde, toda tarde. Aí eu 
perguntei a ela porque o câncer dela só fazia evoluir e tal, aí eu perguntei a ela, falei assim: você acha que assim está te ajudando? Porque ela disse que a cura não iria vim do remédio ia vim dessa terapia, né. Aí eu falei a ela: você acha que está te ajudando? Ela disse: minha filha não sei, mas quem está na minha situação tem que apelar pra qualquer coisa. Eu acredito nisso, eu acho que se eu for curada é mais por isso do que pelo remédio, porque o remédio quanta gente toma o remédio e não vivi, então... (Açucena).

A presença de padres, pastores, rabinos, xeques, pais ou mães-de-santo podem ajudar o paciente a morrer em paz, desde que estejam verdadeiramente imbuídos do espírito sacerdotal. ${ }^{(1)}$

Pode-se destacar que além de trazer conforto e alívio, a aproximação entre o paciente e a religião também incentiva sua expectativa de cura, de melhora ou de um milagre que possa acontecer.

O depoimento do entrevistado aponta como há uma aproximação muitas vezes "fervorosa" do paciente terminal da religião, buscam uma maior proximidade através das orações, das imagens, algo que venha remeter sua fé, que venha lhe trazer apoio. Conforme o relato a seguir:

Eu acho que todo mundo que tem um diagnóstico de terminal vira religioso. Quem não é vira, nunca vi, pode ser que tenha, mas eu nunca vi um paciente que tenha o diagnóstico terminal que não tenha um santinho, que não reze, que não... [...] (Açucena).

Estudiosos e profissionais de saúde percebem que diante das urgências pessoas dos indivíduos, estão presentes as crenças e práticas religiosas (prece, peregrinação, jejum) que ajudam na resolução e seus problemas, além de prevenir ou aliviar consequências emocionais negativas. $^{(10)}$

Outro entrevistado refere que todos os pacientes em situação de "perigo", de sofrimento e de morte se aproximam inevitavelmente de Deus. Pode-se confirmar esta observação no depoimento abaixo:

[...] Eu acho que Deus influencia em todo mundo porque todo mundo fala: ai meu Deus se tiver que ir pra perto do Senhor que me deixe em um bom lugar! Mas não, em dizer assim aceitação, a religião depende muito do ser humano, cada um no desespero todo mundo chama por Deus [...] (Girassol). 
Estudos revelam que o bem-estar espiritual parece estar associado com menores índices de depressão, suicídio, desejo de morte e desesperança em pacientes terminais. ${ }^{(1)}$

Segue os relatos de alguns enfermeiros que afirmam que diante da dificuldade e de uma situação de perigo os pacientes se aproximam de Deus, buscam algo na religião:

[...] Você encontra mais ele dizer buscar a fé, a questão do Deus mesmo, aqui a gente vê claramente, assim não só, cada um tem seu Deus, a gente percebe muito isso, cada um tem sua crença, acredita e então dentro daquilo que acredita tem a sua fé, sua esperança (Violeta).

[...] eles se apegam muito a Deus, muito a Deus, muitas vezes o paciente é religioso ou também às vezes não é religioso, nunca frequentou nada, mas nesse momento assim se apega a Deus [...] (Rosa).

O paciente reafirma e/ou reencontra sua fé religiosa, para assim, utiliza-la como força propulsora para um melhor enfrentamento e superação das dificuldades. ${ }^{(1)}$

Diante de uma doença grave com um prognóstico restrito, a religiosidade ajuda na avaliação e na regulação da resposta, interferindo no sentido que o indivíduo dá as dificuldades, aos limites e ao sofrimento. ${ }^{(10)}$

Logo, entendemos que para o paciente é importante buscar segurança, conforto e esperança através da religião, pois auxilia no enfrentamento do processo de adoecimento e morte.

O paciente diante de sua realidade doença-morte, em alguns momentos utiliza-se da estratégia de barganhar com Deus mais uma oportunidade de continuar a viver, ou pelo menos adiar por mais um tempo a sua morte. Ao utilizar desse recurso o paciente demonstra como sua religiosidade influencia e alimenta sua esperança em alguma mudança que possa ocorrer em seu quadro clinico, ou seja, a religião está intimamente ligada à esperança. Os discursos abaixo relatam este fato:

[...] Geralmente mostram quando vêm pra aqui, é um paciente num estágio mais evoluído. É um paciente que vem do tratamento ambulatorial e aí chega pra gente. $E$ a questão da... Eu já senti aquela questão da barganha, já senti aquela questão da barganha [...] (Cravo).

A barganha é uma tentativa do paciente adiar a morte, oferecendo assim um prêmio "por bom comportamento". A maioria das barganhas são feitas com Deus, sendo mantidas geralmente em segredo, faladas em entrelinhas ou no confessionário do capelão. ${ }^{(11)}$ Pode-se 
observar na fala abaixo a presença da aproximação religiosa pelo paciente no sentido de buscar uma oportunidade de mudança ou até mesmo absolvição, sendo que o paciente relaciona seu adoecimento com seu distanciamento religioso:

[...] Até porque é uma maneira que eles acham que se aproximar de Deus, de pedir desculpas, porque muita gente..., eu já vi um paciente dizer bem assim: ah enfermeira, eu tenho essa doença porque eu não tinha Deus! [...] (Açucena).

Os profissionais de saúde entendem a dificuldade de fazer com que muitos pacientes deixem de ligar a doença a pecados, a culpas ou punição, porque o paciente com tais ideias pode deixar de lutar pela vida, pois acredita que a doença (ou mesmo a morte) seja merecida. A depender de como o paciente lide com sua religião, ela tanto pode consolar as pessoas como fazê-las culpadas e dignas de punição. ${ }^{(1)}$

Constata-se que a maioria dos entrevistados responderam quando questionados se percebiam relação entre religiosidade e melhor aceitação da morte. Dentre os dez enfermeiros, quatro relatam que a religião influencia na aceitação do paciente para com a sua morte e três enfermeiros referiram que não percebem nenhum tipo de relação entre aceitação e religião. Durante o desenvolvimento das entrevistas, nas falas de seis enfermeiros, apareceram manifestações de apego religioso de alguns pacientes que viviam a proximidade da morte e apenas um enfermeiro citou a estratégia de barganha de alguns pacientes.

\section{CONCLUSÃO}

Os relatos expostos pelos enfermeiros revelaram que a maioria deles, percebiam que a religião influenciava na aceitação da morte pelo paciente, porém alguns referiram não encontrar nenhum tipo de relação entre aceitação da morte e religião. Foram também encontradas manifestações de "apego" religioso de alguns pacientes frente à possibilidade da morte, sendo referida a estratégia de barganha e orações como forma de conforto e esperança.

Compreendemos que o homem, há muito tempo, vem buscando na religião respostas para grandes mistérios que cercam o seu imaginário, dentre eles o fenômeno da morte. Logo, entendemos como princípios, ideias e convicções religiosas estão presentes na sociedade e como estes implicam bastante na relação que cada indivíduo possui em sua vida, principalmente na forma de enfrentamento das dificuldades. 
Para o paciente terminal vivenciar o processo de finitude torna-se uma tarefa muito difícil e angustiante. Muitos encontram na religião apoio e respostas que aliviam seu sofrimento. Assim, cabe ao enfermeiro perceber como a religiosidade influencia positivamente no cuidar e utilizar desses artifícios para melhor prestar a assistência de enfermagem.

Logo, o estudo possibilitou o entendimento a respeito da relação existente entre religiosidade e enfrentamento da morte. Portanto, sendo preciso que os enfermeiros se apropriem dessas informações e trabalhem com os aspectos religiosos no cuidar integral e holístico.

Há uma necessidade ainda presente de estudar mais e investigar a influencia da religião, sobretudo nas experiências humanas relacionadas ao sofrimento e processo de morte e morrer. Para isso é preciso que os enfermeiros compreendam essa realidade e queiram estudar e aplicar tais conhecimentos no seu cotidiano profissional.

\section{REFERÊNCIAS}

1. Santos FS. Cuidados Paliativos: Discutindo a vida, a morte e o morrer. São Paulo: Atheneu; 2009. 447p.

2. Faria JB, Seidl EMF. Religiosidade e enfrentamento em contextos de saúde e doença: revisão da literatura. Psicologia: Reflexão e Crítica. 2005; 18(3): 381-389.

3. Oliveira SL. Tratado de metodologia científica: projetos de pesquisa, TGI, TCC, monografias, dissertações e teses. São Paulo: Pioneira Thomson Learning; 2002. 320p.

4. Gil AC. Como elaborar projetos de pesquisa. $4^{a}$ ed. Atlas: São Paulo; 2002. 175p.

5. Minayo MCS. Pesquisa social: teoria, método e criatividade. $9^{\mathrm{a}}$ ed. Petrópolis, RJ: Vozes; 1996. 80p.

6. Brasil. Conselho Nacional de Saúde. Resolução nº 196, de 10 de outubro de 1996. Dispõe sobre diretrizes e normas regulamentadoras de pesquisas envolvendo seres humanos. Bioética. 1996; 4(2 supl): 15-25.

7. Kovács MJ. Morte e existência humana: caminhos de cuidados e possibilidades de intervenção. Rio de Janeiro: Guanabara Koogan; 2008. 222p.

8. Kovács MJ. Morte e desenvolvimento humano. São Paulo: Casa do Psicólogo; 2010. 253p.

9. Hennezel M, Leloup J. A arte de morrer: tradições religiosas e espiritualidade humanista diante da morte na atualidade. $10^{\mathrm{a}}$ ed. Petrópolis, RJ: Vozes; 2009. 143p. 
10. Barbosa KA, Freitas MH. Religiosidade e atitude diante da morte em idosos sob cuidados paliativos. Revista Kairós. 2009; 12(1): 113-134.

11. Kübler-Ross E. Sobre a morte e o morrer. Trad. Paulo Menezes. $9^{\mathrm{a}}$ ed. São Paulo: Martins Fontes; 2008. 296p. 